Research Article

\title{
Study on Field Test and Seismic Performance of MJS Joint Microdisturbance Reinforcement on Existing Tunnel
}

\author{
Zhanyou Luo $\mathbb{D}^{1,2,3}$ Yongheng Deng $\mathbb{D}^{1},{ }^{1}$ Baoping Zou $\mathbb{D}^{1},{ }^{1}$ Jianfeng Zhu ${ }^{1}{ }^{1}$ \\ Mingyao Jiang $\mathbb{B},{ }^{1}$ and Kuangqin Xie $\mathbb{C}^{1}$ \\ ${ }^{1}$ Tunnel and Underground Space Academy, Zhejiang University of Science and Technology, Hangzhou 310023, Zhejiang, China \\ ${ }^{2}$ Institute of Rock Mechanics, Ningbo University, Ningbo 315211, Zhejiang, China \\ ${ }^{3}$ Department of Civil Engineering, Shaoxing University, Shaoxing 312000, Zhejiang, China
}

Correspondence should be addressed to Zhanyou Luo; lzy0395@163.com

Received 21 July 2021; Revised 3 September 2021; Accepted 15 September 2021; Published 25 September 2021

Academic Editor: Zonglong Mu

Copyright (C) 2021 Zhanyou Luo et al. This is an open access article distributed under the Creative Commons Attribution License, which permits unrestricted use, distribution, and reproduction in any medium, provided the original work is properly cited.

Metro Jet System (MJS) joint microdisturbance reinforcement is often adopted to strengthen and remediate existing tunnels that are severely deformed by under-construction peripheral works, but analysis related to the reinforcement system of tunnel under consideration of seismic effects is insufficient at present. In this work, a field test of MJS joint microdisturbance reinforcement system of existing tunnels was conducted on the basis of a subway tunnel deformation reinforcement project. Then, a numerical simulation study of the seismic dynamic response of reinforcement system was performed in combination with seismic wave direction and intensity. Results show that the MJS joint microdisturbance reinforcement measures can effectively reduce the settlement and horizontal radial convergence deformation of the tunnel. The seismic longitudinal wave significantly affects the vertical displacement of the tunnel, and the seismic-induced vertical displacement of the tunnel increases with the rise in seismic intensity. The seismic transverse wave significantly affects the horizontal radial convergence deformation of the tunnel, and the seismic-induced horizontal radial convergence deformation of the tunnel increases with the rise in seismic intensity. The antiseismic property of MJS joint microdisturbance reinforcement measures on the existing tunnel is not obvious.

\section{Introduction}

The impact of the surrounding construction in progress can cause damage to the operating tunnel, which can cause deformation in the operating tunnel in severe cases and affect the safe use of the tunnel [1]. Lateral grouting reinforcement system is used for remediation for tunnels with small deformations, while MJS joint microdisturbance reinforcement construction measures are used for remediation for tunnels that produce severe deformations. The reason is that the effect of seismic effects on existing tunnels reinforced by MJS joint microdisturbance reinforcement is not well understood. Accordingly, the seismic dynamic response of tunnels and reinforcement systems needs to be explored. In the study of earthquake effects on tunnels, Zhang et al. [2] and Lai et al. [3] used numerical simulations and indoor tests to examine the dynamic response of tunnels under earthquake effects, respectively. They found that underpass tunnels have certain effects on the seismic response of aboveground frames and obtained the tunnel vibration acceleration response law. Guan et al. [4] studied the seismic dynamic response of an extra-large section tunnel under bias pressure conditions and found that the bias pressure effect will show an amplification law as the ground vibration amplitude increases. Zhang and Lei [5] used FLAC threedimensional software to establish a two-dimensional finite element model of the tunnel under seismic action and analyzed the effect of seismic parameters on the tunnel. Pakbaz and Yareevand [6] and $\mathrm{Xu}$ et al. [7] used finite element analysis software to investigate the main causes of tunnel damage by simulating the interaction between the tunnel lining structure and the surrounding rock. They also proposed tunnel reinforcement measures. Hleibieh et al. [8] and Kawakami [9] estimated the tunnel deformation by 
establishing a seismic dynamic response model and a fractured strata mechanics model, respectively. They obtained seismic design parameters for tunnels in earthquake zones. In the simulation of tunnel grouting reinforcement, Deng [10] analyzed the extent of grouting reinforcement system and the amount of soil uplift by multipoint displacement meter to obtain the parameters of grouting reinforcement system in the unevenly settled section of the tunnel. Xu et al. [11] used numerical simulation to study the reinforcement range of reasonable grouting of soil around the existing tunnel structure and obtained the law of ground deformation with the depth of grouting reinforcement. Xiao [12] used the microdisturbance dual-liquid grouting technology to strengthen the converging deformation tunnel and found a better grouting effect on both sides of the tunnel. Zhang et al. [13] analyzed the mechanism and main influencing factors of split grouting reinforcement in silty strata, and the comparison with experimental results showed that split grouting reinforcement is feasible. Xiong et al. [14] used finite elements to simulate the reinforcement of the MJS method for the starting section of the shield machine and obtained the construction parameters with good reinforcement effect. Jin et al. [15] conducted cement grouting field tests for in situ and remodeled loess and obtained the relationship curves between grouting volume and time under different grouting pressures, which revealed the diffusion mechanism of cement slurry in loess. In summary, although scholars have investigated the seismic dynamic response of reinforcement system for tunnels, research on the seismic response of existing tunnels strengthened by MJS joint microdisturbance is insufficient. Therefore, in this work, a field test of MJS joint microdisturbance reinforcement reinforced existing tunnel is conducted on the basis of an underpass tunnel deformation reinforcement project. Then, a numerical simulation study of the seismic dynamic response of reinforcement system is performed by combining seismic wave direction and intensity.

\section{Project Overview}

An operational subway tunnel is located below the construction in progress, the average vertical distance from the top of the tunnel to the ground is $18 \mathrm{~m}$, the outer diameter of the tunnel segment is $6.1 \mathrm{~m}$, the inner diameter is $5.5 \mathrm{~m}$, the wall thickness is $0.3 \mathrm{~m}$, the tunnel section is circular, the lining structure is made of high-strength precast reinforced concrete, the width of each ring is $1.2 \mathrm{~m}$, the concrete strength grade is C50, and the material parameters of the segment and the main reinforcement materials are shown in Table 1 . The area where the project is located belongs to alluvial plain terrain, and the geological parameters of the soil layer obtained from the site borehole exploration and regional geological data are shown in Table 2. The seismic zoning map indicates that the seismic intensity level of the area where the project is located is VI.

Given that the tunnel was affected by the construction of the surrounding under-construction projects, the operated subway tunnel produced horizontal radial convergence deformation, and Figure 1(a) shows a schematic of the tunnel segment deformation. Notably, $\Delta \mathrm{D}$ is the difference between the diameter of the tunnel after deformation and the original tunnel diameter. For the sake of description, the horizontal radial convergence data mentioned in the latter are $\Delta D / 2$. Figure 1 (b) shows a graph of the horizontal radial convergence deformation curve of the tunnel segment. The graph indicates that the maximum horizontal radial convergence deformation value of the tunnel reaches $57.30 \mathrm{~mm}$. As a result, the tunnel with more serious deformation of rings $100-113$ needs to be reinforced by MJS joint microdisturbance. The plan layout of MJS and microdisturbance grouting hole location is shown in Figure 2. The center distance of MJS grouting hole is $1.8 \mathrm{~m}$, the center distance of microdisturbance grouting hole is $1.2 \mathrm{~m}$, and the total length of reinforced section is $16.8 \mathrm{~m}$. The location relationship between the reinforcement of MJS joint microdisturbance reinforcement and the tunnel is shown in Figure 3.

\section{Determination of Model Parameters}

3.1. MJS Grouting Simulation. In this project, the MJS grouting reinforcement system is first conducted by drilling holes at the designed points. Then, high-pressure injection grouting is performed at the depth to be reinforced. The lower part of the MJS grouting reinforcement system is cylindrical with a cement dosage of $3.3 \mathrm{t} / \mathrm{m}$, and the upper part is semicylindrical with a cement dosage of $1.65 \mathrm{t} / \mathrm{m}$. The internal pressure is achieved by adjusting the forced slurry discharge [16]. The internal pressure coefficient is controlled between 1.3 and 1.6 during construction, and the watercement ratio is $1: 1$ and the pile diameter is $1.2 \mathrm{~m}$. The construction parameters in this project are used as the numerical simulation parameters for the MJS grouting reinforcement system, and the boundary pressure of the MJS grouting reinforcement system in the finite element model is determined by the internal pressure coefficient [17]. The simulation of the MJS reinforcement system is divided into the following two steps. (1) The soil modeling is performed first; then, the soil at the location of the MJS grouting reinforcement system is removed, and the internal pressure coefficient is applied with the actual engineering. The normal contact between MJS and soil is set as surface contact, and tangential contact is set as friction contact. (2) The MJS grouting reinforcement system is activated first when the calculation is completed; then, the internal pressure coefficient applied to the soil boundary is removed.

3.2. Microdisturbance Grouting Simulation. The microdisturbance grouting method first creates a splitting and encrypting effect on the soil by pouring slurry into the soil at the design point to form a grouting body [18]. In this project, the diameter of the grouting pipe is $32 \mathrm{~mm}$, the flow rate of cement slurry is $14-16 \mathrm{~L} / \mathrm{min}$, the flow rate of water glass is $5-10 \mathrm{~L} / \mathrm{min}$, and the grouting pipe is lifted $5 \mathrm{~cm}$ every $30 \mathrm{~s}$. The expansion coefficient of the grouted body is obtained by calculating the increment of the grouting volume to obtain the compaction effect. Without the volume expansion in vertical orientation after slurry injection, the cross-sectional 
TABLE 1: Calculation parameters of tunnel segment and reinforcement materials.

\begin{tabular}{lccc}
\hline Material & Weight $\left(\mathrm{kN} / \mathrm{m}^{3}\right)$ & Elastic modulus $(\mathrm{MPa})$ & Poisson's ratio \\
\hline Tunnel pipe & 25.0 & 34,500 & 0.2 \\
MJS pile & 22.0 & 2,800 & 0.2 \\
Microdisturbance grouting & 24.0 & 2,800 & 0.2 \\
\hline
\end{tabular}

TABle 2: Physical and mechanical parameters of the soil.

\begin{tabular}{lccccc}
\hline Material & Weight $\left(\mathrm{kN} / \mathrm{m}^{3}\right)$ & Elastic modulus $(\mathrm{MPa})$ & Poisson's ratio & Cohesion $(\mathrm{MPa})$ & Internal friction angle $\left(^{\circ}\right)$ \\
\hline Miscellaneous fill & 18.0 & 16.50 & 0.26 & 10.0 & 10.0 \\
Sandy silt & 18.1 & 35.00 & 0.25 & 5.0 & 27.5 \\
Muddy-silty clay & 17.4 & 30.00 & 0.25 & 14.2 & 11.5 \\
Muddy-silty clay with slit & 18.2 & 30.00 & 0.25 & 13.0 & 19.0 \\
Silty clay & 17.6 & 32.00 & 0.25 & 16.2 & 14.5 \\
\hline
\end{tabular}

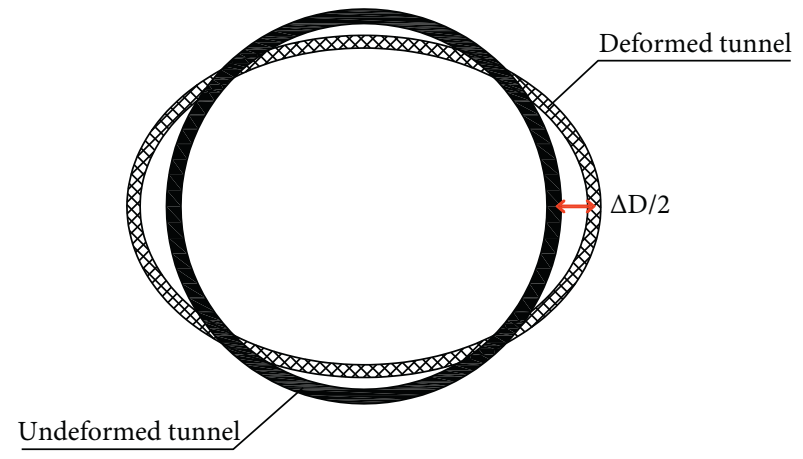

(a)

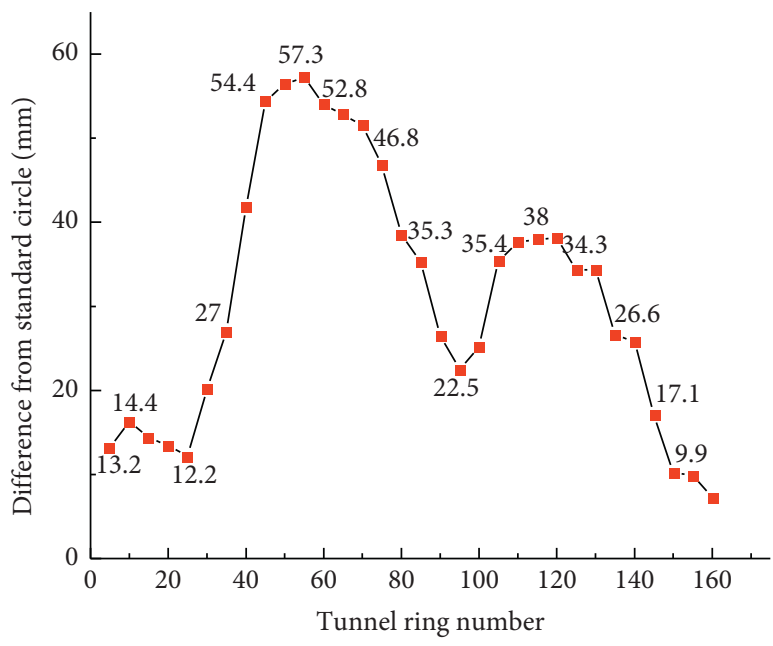

(b)

FIGURE 1: Horizontal radial convergence diagram of tunnel segment: (a) tunnel deformation diagram and (b) horizontal radial convergence deformation curve of tunnel segment.

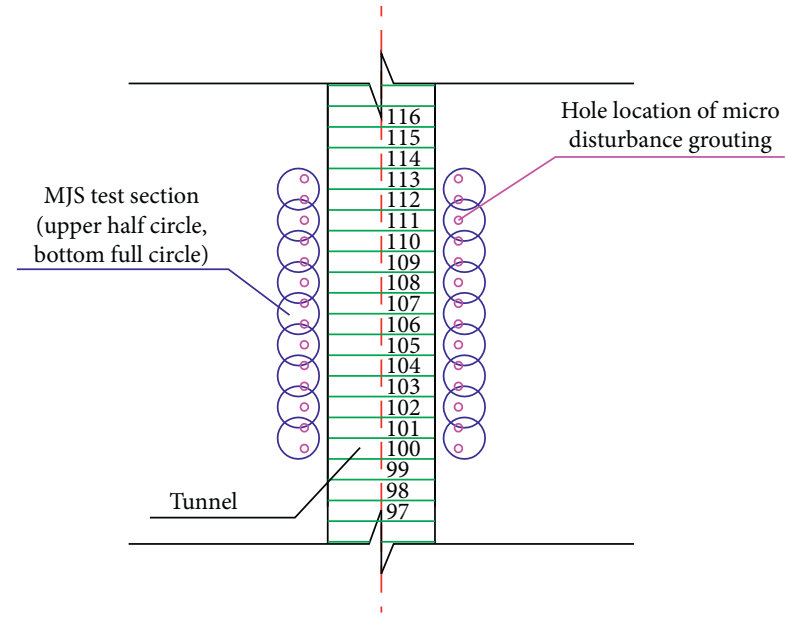

Figure 2: Plan layout of MJS joint microdisturbance reinforcement.

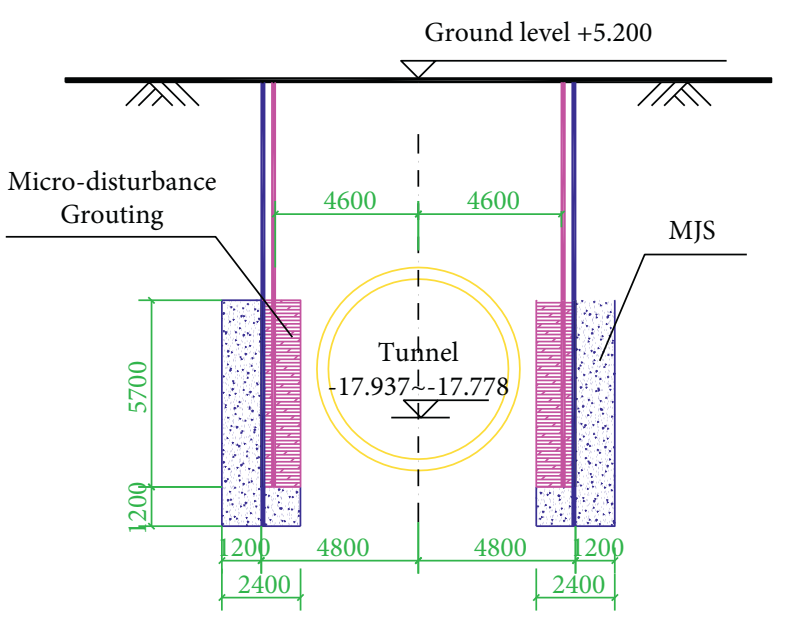

FIGURE 3: Location relationship of the MJS joint microdisturbance reinforced existing tunnel. 
area at the beginning of grouting is $803.84 \mathrm{~mm}^{2}$, which reaches $2250 \mathrm{~mm}^{2}$ after grouting. Therefore, the volume expansion is 2.8 times. The construction parameters in this project are used as the numerical simulation parameters for the microdisturbance grouting reinforcement system, and the simulation of microdisturbance grouting reinforcement system is divided into the following two steps. (1) The soil on the location of the microdisturbance grouting reinforcement system is removed, and the microdisturbance grouting body is activated. (2) The pressure is applied to the surface of the microdisturbance grouting body after the calculation is completed. As a result, the volume of the original part is laterally expanded to 2.8 times the original volume. The normal contact between the microdisturbance grouting reinforcement system and the soil is set as surface contact, and the tangential contact is set as friction contact.

3.3. Seismic Effect Simulation. In investigating the interaction between the tunnel and the reinforcement system under earthquake action, the longitudinal waves, transverse waves, and seismic intensity of the earthquake can be simulated by setting the corresponding displacement directions and parameters at the model boundary. The seismic intensity of the area is VI. Thus, the three levels of seismic intensity selected are V, VI, and VII, and the corresponding accelerations are $0.31,0.63$, and $1.25 \mathrm{~g}$, respectively [19].

\section{Three-Dimensional Numerical Modeling}

In establishing a three-dimensional numerical model of the seismic dynamic response of the tunnel and the reinforcement system under seismic action, the assumptions are that the tunnel segment and the grouted body are elastic materials, the soil is isotropic elastic-plastic material, and the Mohr-Coulomb yield criterion is chosen. The geometry of the model is determined by the actual reinforcement range; the upper boundary of the model is the ground surface; the lower boundary is taken as $3 \mathrm{D}$ below the bottom of the tunnel ( $\mathrm{D}$ is the inner diameter of the tunnel); the horizontal boundary is taken as 6D; the axial length of the model is taken as twice the length of the construction section; the length, width, and height of the three-dimensional finite element model are taken as $50 \mathrm{~m}$; the sides and bottom of the model are constrained by displacement; and the ground surface is set as unconstrained, as shown in Figure 4. The specific steps of the simulation process are as follows. (1) The ground stress is balanced. The original soil ground stress equilibrium is established, and the initial ground state is simulated. (2) The tunnel is set up. The original soil in the tunnel part is removed and replaced by the tunnel. The contact state between the tunnel and the soil is set. (3) Surface load simulation is conducted. The pressure at the surface above the tunnel is set up to ensure that the deformation of the tunnel is consistent with the actual deformation of the project. (4) MJS grouting simulation is performed. The original soil at the MJS site is removed, the internal pressure coefficient of 1.3-1.6 is applied on the boundary, and the boundary conditions of internal pressure

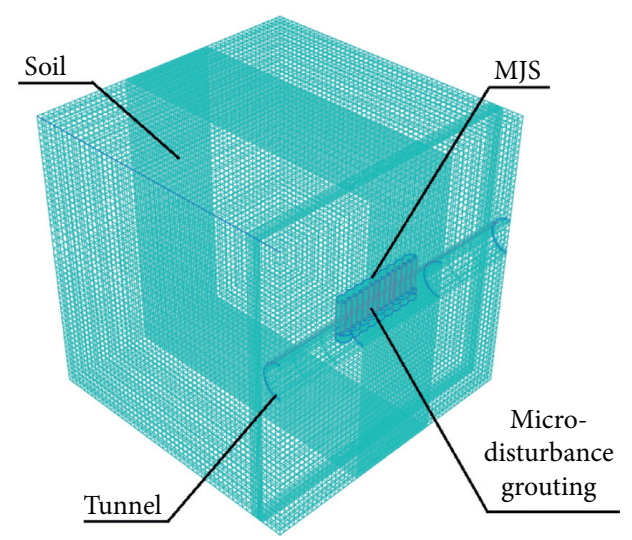

Figure 4: Three-dimensional view of the model.

after replacing the components with MJS properties are eliminated. (5) Microdisturbance grouting simulation is done. The original soil at the microdisturbance site is removed, the parts with the properties of microdisturbance grouting body are replaced, and physical force is applied on the parts to expand their volume by 2.8 times the original. After they are stabilized, the reinforcement construction work is finalized. (6) Seismic load simulation is carried out by imposing boundary conditions with corresponding parameters on the model boundary.

\section{Analysis of Calculation Results}

5.1. Validation of Three-Dimensional Models. The measured and numerical simulated values of horizontal radial convergence deformation of tunnel reinforcement by MJS joint microdisturbance reinforcement in the project are compared to verify the accuracy of the model. Figure 5 shows the horizontal radial convergence deformation of the tunnel segment before and after the MJS reinforcement, and Figure 6 shows the comparison between the measured and simulated values of the tunnel segment after the MJS reinforcement. As shown in Figures 5 and 6, the measured maximum value of the convergence deformation in the reinforced section reaches $4 \mathrm{~mm}$, and the maximum value in the numerical simulation reaches $3.53 \mathrm{~mm}$. The change pattern of the two is more consistent.

Figure 7 shows the comparison of measured and simulated values of convergence deformation and vertical displacement after microdisturbance grouting reinforcement. As shown in Figure 7(a), the measured maximum value of convergence deformation reaches $17.74 \mathrm{~mm}$ in the reinforced section, and the maximum value reaches $29.50 \mathrm{~mm}$ in the numerical simulation. The variation law of the convergence deformation and vertical displacement is consistent between the measurement and simulation.

5.2. Analysis of Dynamic Response of Reinforcements under Seismic Action. Numerical simulation analysis is conducted for different earthquake directions and intensities to obtain the results of the seismic dynamic response of the tunnel reinforcement, and the corresponding laws can be obtained. 


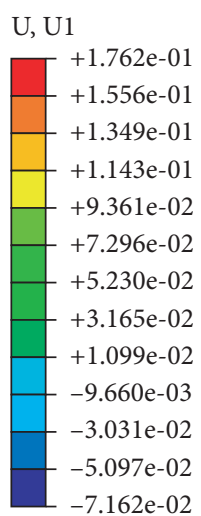

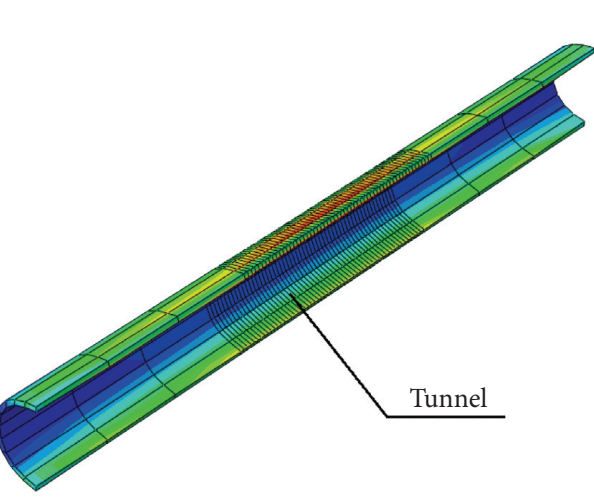

(a)

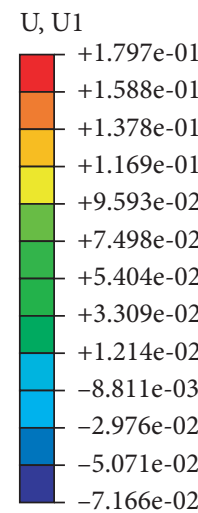

$-7.166 \mathrm{e}-02$

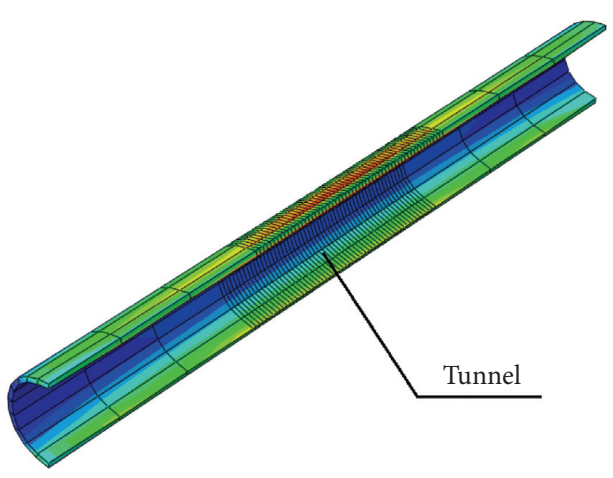

(b)

FIGURE 5: Horizontal radial convergence deformation cloud of tunnel segment before and after MJS reinforcement: (a) before reinforcement and (b) after reinforcement.

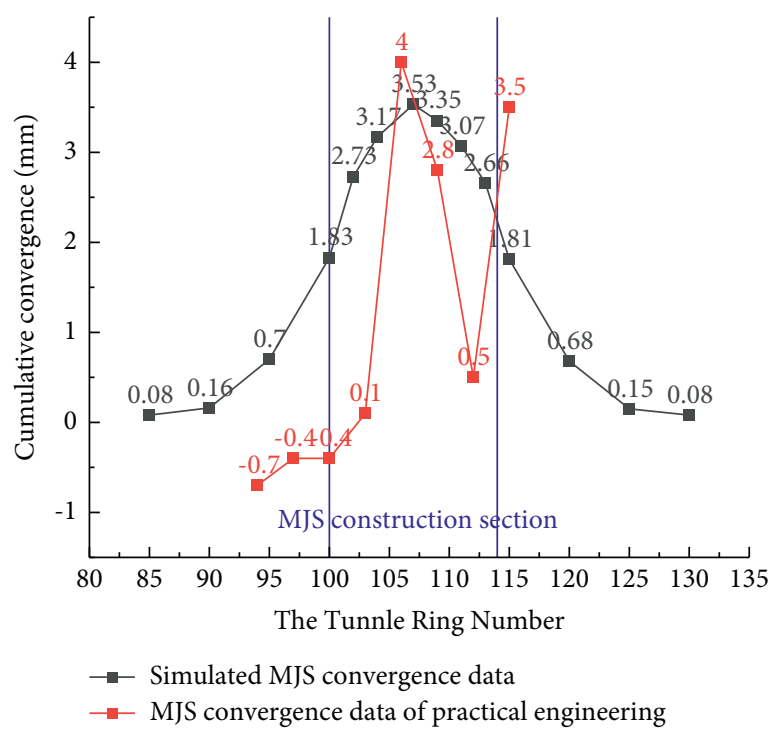

FIGURE 6: Comparison of measured and simulated values of convergence deformation after MJS reinforcement.

Figure 8 shows the comparison of the horizontal radial convergence and vertical displacement of the tunnel segment under the action of earthquake longitudinal waves at different seismic intensities. As shown in Figure 8, (1) the maximum horizontal radial convergence deformation values of the tunnel segment in the reinforced section under the action of three seismic intensities from V to VII are $0.13,0.67$, and $0.58 \mathrm{~mm}$, respectively (the values are produced by the action of the earthquake). (2) The maximum vertical uplift values of the reinforced section of the tunnel segment under the action of three seismic intensities from V to VII are 4.93, 19.38, and $39.68 \mathrm{~mm}$, respectively. (3) Under the action of three seismic intensities from V to VII, the maximum horizontal radial convergence deformation values of the nonreinforced section of the tunnel segment reach $0.91,1.32$, and $1.17 \mathrm{~mm}$, respectively. Meanwhile, the maximum vertical uplift values reach $6.67,19.58$, and $40.00 \mathrm{~mm}$. (4) The horizontal radial convergence deformation values of the reinforced tunnel sheet are $0.78,0.65$, and $0.59 \mathrm{~mm}$ smaller than those of the nonreinforced tunnel sheet. Meanwhile, the vertical uplift values are $1.74,0.2$, and $0.3 \mathrm{~mm}$ smaller.

Figure 9 shows the comparison of horizontal radial convergence and vertical displacement of the tunnel segment under the action of different seismic intensities by seismic transverse waves. As shown in Figure 9, (1) the maximum horizontal radial convergence deformation values of the reinforced section tunnel segment under the action of three seismic intensities from V to VII are 11.73, 23.11, and $47.42 \mathrm{~mm}$, respectively. (2) The maximum vertical settlement values of the reinforced section tunnel segment under the action of three seismic intensities from V to VII are $0.165,0.299$, and $0.795 \mathrm{~mm}$, respectively. (3) Under the action of three seismic intensities from V to VII, the maximum horizontal radial convergence deformation values 


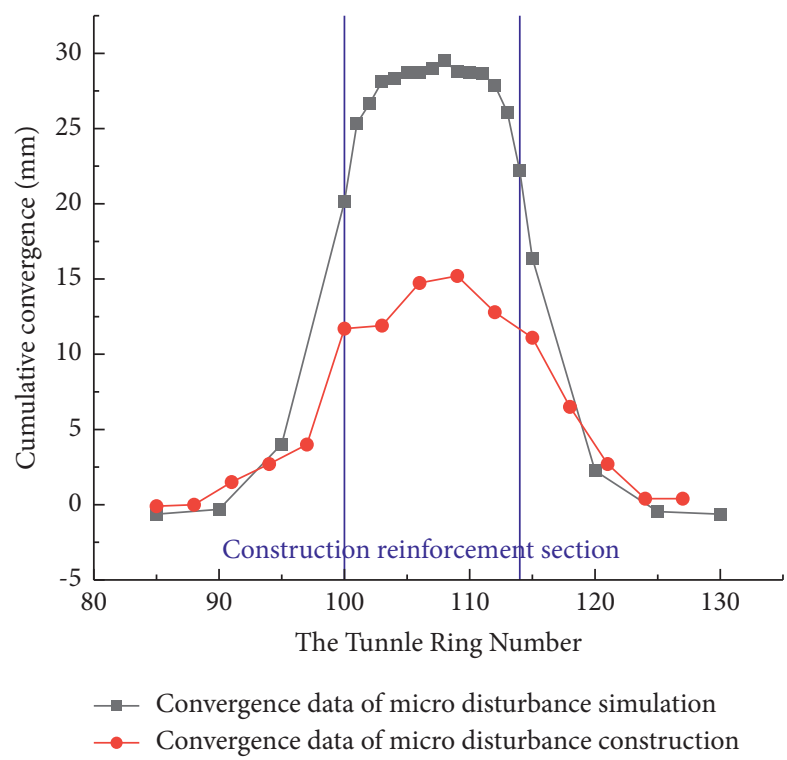

(a)

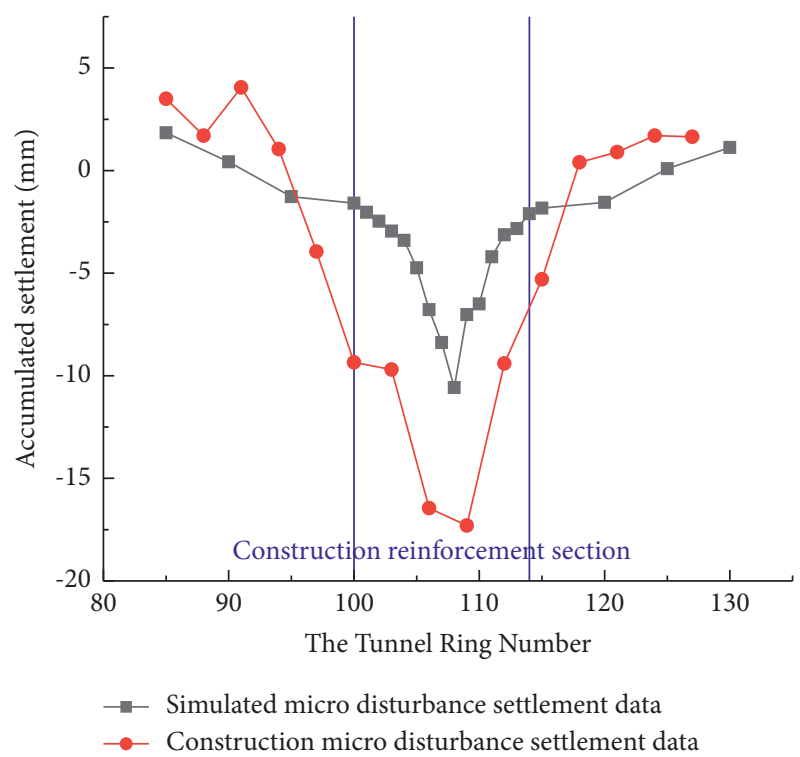

(b)

FiguRE 7: Comparison of measured and simulated values of convergence deformation and vertical displacement after microdisturbance grouting reinforcement: (a) comparison of convergence deformation and (b) comparison of vertical displacement.

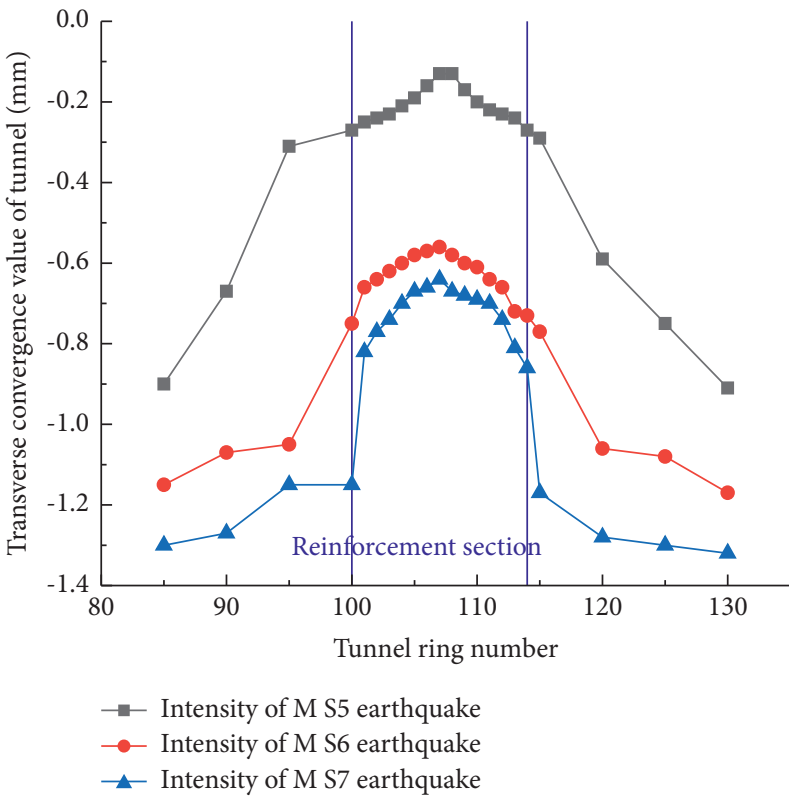

(a)

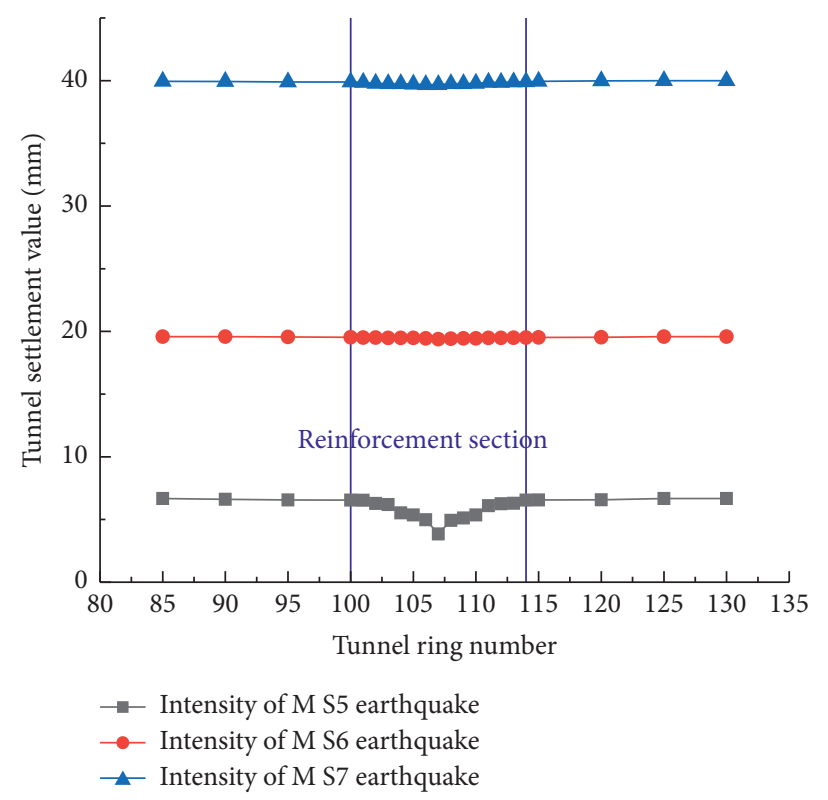

(b)

Figure 8: Comparison of horizontal radial convergence and vertical displacement of the tunnel segment under the action of seismic longitudinal waves at different intensities: (a) convergence deformation and (b) vertical displacement.

of the tunnel segment in the nonreinforced section reach $11.742,23.23$, and $47.65 \mathrm{~mm}$, respectively. Meanwhile, the maximum vertical settlement values reach $0.179,0.374$, and $0.864 \mathrm{~mm}$. (4) The horizontal radial convergence deformation values of the reinforced tunnel sheet are $0.012,0.12$, and $0.23 \mathrm{~mm}$ smaller than those of the nonreinforced tunnel sheet. Meanwhile, the vertical settlement values are 0.014 , 0.075 , and $0.069 \mathrm{~mm}$ smaller.
5.3. Seismic Response of MJS Reinforcement System. Figure 10 shows the stress clouds of the MJS reinforcement system under the action of seismic longitudinal waves at seismic intensities V-VII. As shown in the figure, no stress concentration is present in the semicylindrical region of MJS reinforcement, and stress concentration is observed in the cylindrical region, and it shows irregular distribution. The stress inside the MJS reinforcement increases with the rise in 


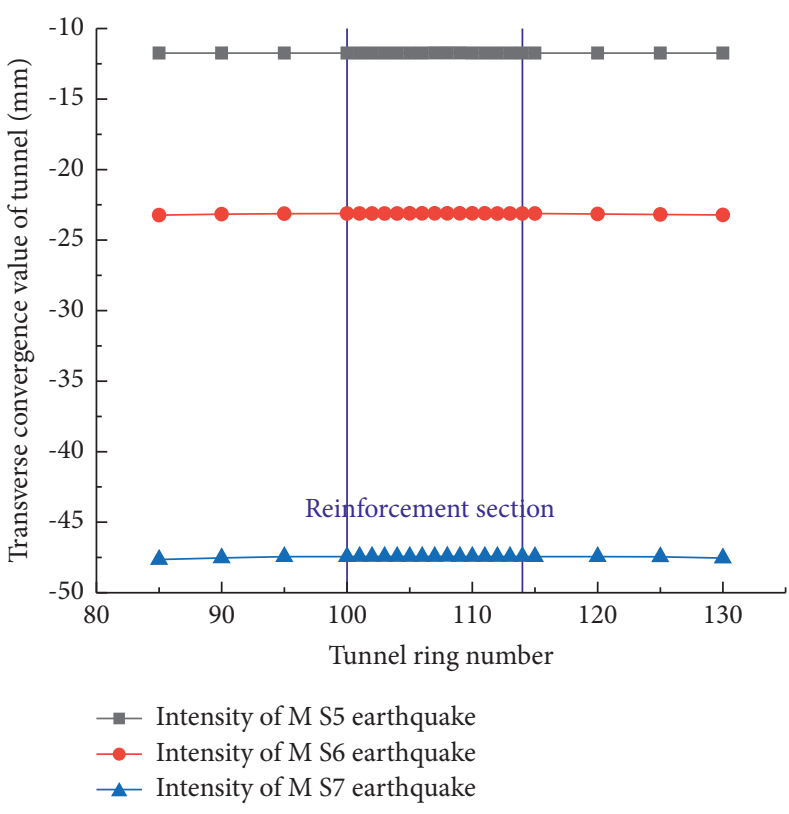

(a)

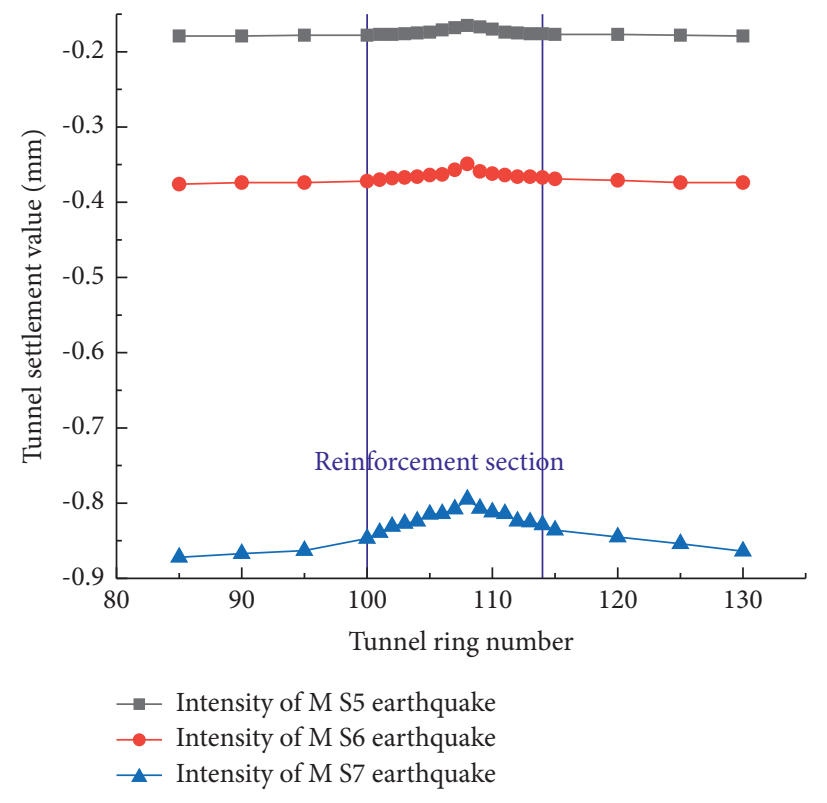

(b)

Figure 9: Comparison of horizontal radial convergence and vertical displacement of tunnel segment under different intensities of seismic transverse waves: (a) convergence deformation and (b) vertical displacement.

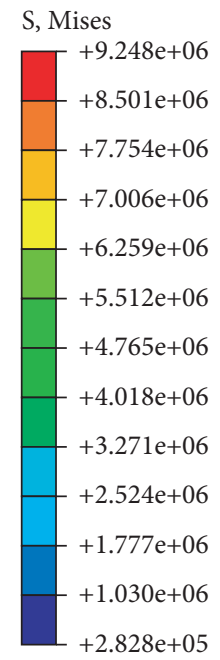

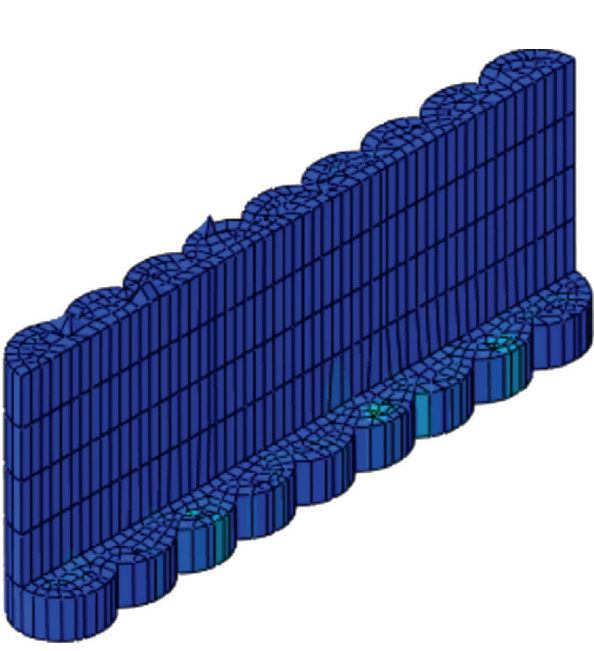

(a)

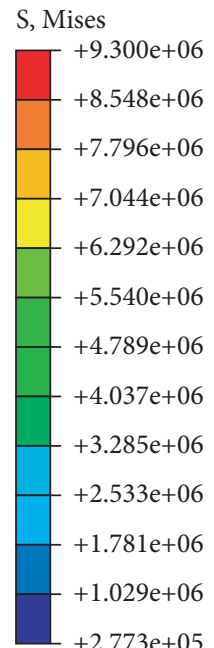

$+2.773 \mathrm{e}+05$

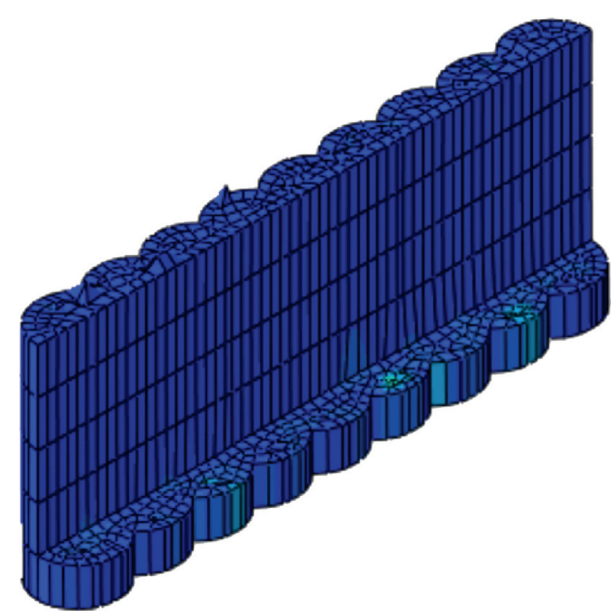

(b)

FIgURE 10: Continued. 


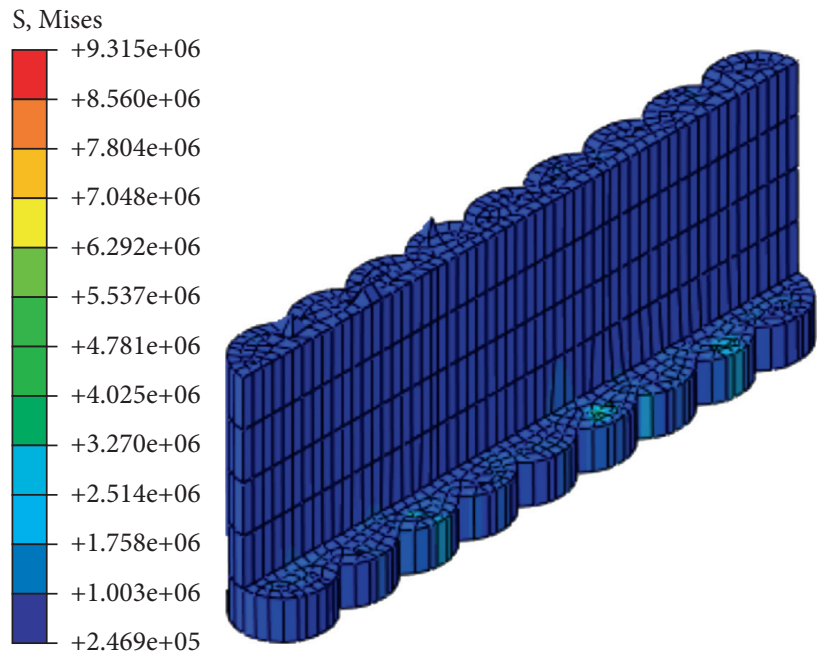

(c)

FIGURE 10: Stress clouds of MJS reinforcement under the action of V-VII seismic intensities: (a) earthquake intensity of V, (b) earthquake intensity of VI, and (c) earthquake intensity of VII.

seismic intensity, and the maximum stress values are 9.25 , 9.30, and $9.32 \mathrm{MPa}$ for seismic intensities $\mathrm{V}$ to VII, respectively.

\section{Conclusions}

In this work, a field test of MJS joint microdisturbance reinforcement of existing tunnels was conducted on the basis of a subway tunnel deformation reinforcement project. Then, a numerical simulation study of the seismic dynamic response of the tunnel reinforcement system was performed in combination with seismic wave direction and intensity. The following main conclusions were obtained:

(1) MJS reinforcement measures can effectively increase the peripheral restraint of the existing tunnel and limit the further expansion of tunnel deformation. The microdisturbance grouting measures can effectively reduce the convergence deformation and settlement of the tunnel.

(2) The seismic longitudinal waves significantly affect the vertical displacement of the tunnel. The seismicinduced vertical displacement of the tunnel increases with the rise in seismic intensity, but the seismic longitudinal waves have less effect on the horizontal radial convergence deformation of the tunnel.

(3) The seismic transverse waves significantly affect horizontal radial convergence deformation of the tunnel. The seismic-induced horizontal radial convergence deformation of the tunnel increases with the rise in seismic intensity, but the seismic transverse wave has less effect on the vertical displacement of the tunnel.

(4) The antiseismic property of MJS joint microdisturbance reinforcement measures on the existing tunnel is not obvious, and the difference in deformation between the reinforced and nonreinforced areas of the existing tunnel caused by the seismic action is small.

\section{Data Availability}

The data used to support the findings of this study are included within the article.

\section{Conflicts of Interest}

The authors declare that there are no conflicts of interest regarding the publication of this paper.

\section{Acknowledgments}

This study was supported by the Key Funding of the New Century 151 Talent Project and the Special Support Plan for High Level Talents of Zhejiang Province. Their support is gratefully acknowledged.

\section{References}

[1] G. Wei and S. M. Zhang, "Review of the research on the influence of ground surcharge on the subway shield tunnel nearby," Low Temperature Architecture Technology, vol. 43, no. 1, pp. 92-97, 2021.

[2] J. Zhang, C. X. Tan, Y. Huang, L. H. Huang, and K. C. Xu, "Dynamic response analyses of soft soil-tunnel-aboveground frame systems under earthquake," Journal of Vibration and Shock, vol. 39, no. 22, pp. 278-286, 2020.

[3] T. W. Lai, H. Lei, and H. G. Wu, "Vibration acceleration responses of crossing tunnels of highway and railway under different directions of seismic loads," China Railway Science, vol. 42, no. 3, pp. 95-104, 2021. 
[4] Z. C. Guan, L. F. Zhu, L. Qiao, and Y. S. Tang, "Seismic response of large-section tunnel with unsymmetrical loading based on numerical simulation," Journal of Basic Science and Engineering, vol. 29, no. 4, pp. 927-938, 2021.

[5] M. Zhang and Z. Lei, "Application of FLAC 3Din earthquake dynamic response inside subway tunnel," Urban Mass Transit Company, vol. 17, no. 4, pp. 47-53, 2014.

[6] M. C. Pakbaz and A. Yareevand, "2-D analysis of circular tunnel against earthquake loading," Tunnelling and Underground Space Technology, vol. 20, no. 5, pp. 411-417, 2005.

[7] Z. H. Xu, H. W. Song, and J. Zhao, "Numerical analysis of stability of tunnel surrounding rocks under earthquake," Journal of China University of Mining and Technology, vol. 33, no. 1, pp. 41-44, 2004.

[8] J. Hleibieh, D. Wegener, and I. Herle, "Numerical simulation of a tunnel surrounded by sand under earthquake using a hypoplastic model," Acta Geotechnica, vol. 9, no. 4, pp. 631-640, 2014.

[9] H. Kawakami, "Evaluation of deformation of tunnel structure due to Izu-Oshima-Kinkai earthquake of 1978," Earthquake Engineering and Structural Dynamics, vol. 12, no. 3, pp. 369-383, 1984.

[10] Z. J. Deng, "Experimental study of two-shot micro-disturbance reinforced grouting," Chinese Journal of Underground Space and Engineering, vol. 7, no. S1, pp. 1344-1346, 2011.

[11] Y. J. Xu, L. J. Tao, W. B. Li, and F. Wang, "Research on the grouting reinforcement range of the soil around the existing tunnel structure in the subway up-crossing project," Railway Engineering, vol. 11, pp. 42-44, 2012.

[12] T. G. Xiao, "Effect analysis on tunnel convergence deformation improvement by double liquid micro-disturbance grouting," Tunnel and Rail Transit, vol. 3, pp. 53-56+62, 2020.

[13] X. Z. Zhang, F. Y. Fu, and X. H. Wang, "Research on fracturing grouting in soft flowing mucky clay," Chinese Journal of Underground Space and Engineering, vol. 4, pp. 405-408+456, 2003.

[14] Z. M. Xiong, Z. H. Qin, H. Cai, and X. B. Wang, "Application and analysis of MJS piles in shield starting of water-rich sandy stratum," Journal of Railway Engineering Society, vol. 38, no. 3, pp. 8-12+64, 2021.

[15] X. Jin, S. L. Zhang, Z. H. Qiu, M. Zhang, and Y. L. Qu, "Field tests of grouting diffusion of cement slurry in loess," Journal of Xi'an Technological University, vol. 41, no. 3, pp. 292-299, 2021.

[16] Z. X. Zhang and J. Y. Li, "Review and applications of MJS techniques for ground improvement," Journal of Civil and Environmental Engineering, vol. 39, no. 6, pp. 1-11, 2017.

[17] F. L. Lian, L. Kou, B. Wang, and R. H. Miao, "Research on the effect of penetration grouting integrated rod on the soil stress of shield tunnel," Highways, vol. 66, no. 3, pp. 370-375, 2021.

[18] Y. Gao, "Application of micro disturbance correction technique for double liquid grouting in shield tunnel disease treatment of Nanjing metro," Urban Mass Transit Company, vol. 18, no. 6, pp. 109-112+129, 2015.

[19] GB/T 17742-2020, GB/T 17742-2020 Code for the Chinese Seismic Intensity Scale, Chinese Seismic Intensity Scale, Beijing, China, 2021, in Chinese. 